\title{
The Management of KG Schools: The Case of Dilla University Community School
}

\author{
Dejene Deme Megersa \\ Department of Educational Planning and Management, Addis Ababa University, Addis Ababa, Ethiopia \\ Email: dejenedeme06@gmail.com
}

Received 25 April 2015; accepted 18 May 2015; published 25 May 2015

Copyright (C) 2015 by author and OALib.

This work is licensed under the Creative Commons Attribution International License (CC BY). http://creativecommons.org/licenses/by/4.0/

(c) (†) Open Access

\section{Abstract}

The purpose of this paper was to explore the management of kindergarten school of Dilla University with reference to the learning environment and the kind of pedagogy employed. To examine the issue under consideration, the study was guided by qualitative case study. Semi-structured interview was the dominant data collection tool. On the basis of their contributions to the study six participants were selected purposefully. The central research questions were, "To what extent the learning environment of Dilla University KG school is conducive to serve its purpose? What pedagogical challenges and opportunities are in place in the management of the school?" The study found that the learning environment is not child friendly. Besides, the play-oriented child driven pedagogy is not yet adequately materialized. More specifically, the study revealed that there was unfavorable learning environment; poor commitment; lack of supervisory support; absence of trainings and re-trainings; and inappropriate mode of assessment. In light of the findings there is a need for adequate pre-service and ongoing trainings to the practitioners. Besides, the supervisory practices should be handled by professionally competent supervisors. Finally, the creation and development of a playful and child-oriented learning environment have been proposed, along with suggestions for further empirical exploration.

\section{Keywords}

Kindergarten, Learning Environment, Pedagogy

Subject Areas: Education

\section{Introduction}

The management of kindergarten (KG) schools plays a key role in the holistic development of a child. Specifically, the existence of child-friendly learning environment has positive repercussions for the well functioning of the schools. Besides, the provision of age appropriate and playful pedagogical approaches could facilitate the 
healthy development of children. Therefore, if children are at the center of KG schools the creation and development of child friendly learning environment remain in the crux of the matter. In the same vein, several studies (e.g., [1]-[4]) confirmed that pre-primary education is a very crucial stage in the overall development of a child. This implies the need for unconditional attention of the school management.

Children attending KG schools with competent school management, well-trained teachers, conducive school environment, play-oriented teaching methodology, relatively low child-to-teacher ratios, and effective parent involvement are more likely to succeed than providers with lower levels of quality [6]. Similarly, the economist James Heckman's research [6] [7] utilizes an economic principle to early learning and confirms that "early success begets later success,"-indicating that children who do not have better early learning practices are more likely to fail [6] [7]. Thus, in this critical stage of education the presence of responsible school management is binding (see the annex for further clarifications).

The management of early childhood education can facilitate or complicate the well functioning of the system. For example, in Ethiopia, the importance of early education was recognized as early as Medieval Ethiopia [4] [8]. Nonetheless, in 2010, the Government launched a "Comprehensive Early Childhood Development Policy Framework and a Strategic Operational Plan” as part of its Education and Training Policy. Therefore, introducing the Early Childhood Care and Education (ECCE) policy for a country that recognized the importance of preprimary education during the $17^{\text {th }}$ century witnessed the low key given to the program [8]-[10].

Although, "the Government of Ethiopia recognizes the pre-primary phase of education for children aged 4 - 6 years" [11], "active engagement in provision has been minimal and in practice, ECCE is mainly provided by the private sector" [12]. However, "the private sector has filled the vacuum of demand in the absence of significant government initiatives, and inevitably functions to benefit the most advantaged urban groups" [13].

Besides, preprimary education is not compulsory. It is dominated by fee charging preprimary schools which mainly supply to the needs of well-to-do parents living in urban areas of the country. Except in some technical support, the Government has limited involvement in this critical stage of education [3] [14].

\section{Statement of the Problem}

A first-class KG school management contributes not only help prepare children for entry into primary schools, but also provides a foundation for later success [15]. Some of its ingredients such as a positive learning environment and the existence of appropriate pedagogy could serve as the bedrock upon which excellent basic and sound KG education is built [16]. Consequently, "a good number of children and families benefit worldwide through participating in high-quality, well-proven early childhood programs run by dedicated and skilled professionals" [17]. Regardless of this fact, the issue of Early Childhood Development and Education has not been given the concern and attention it ought to have by responsible child protection parties in Africa [18].

Surprisingly, though modern KG was introduced in Ethiopia in 1900, "pre-school education still remains in an embryonic state and very unequally spread out in the country" [4] [8]. For instance, the expansion rate of the subsector is very undersized. According to the recent data from the Education Statistics Annual Abstract of 2011/12, in 2004 E.C there were only 3,580 kindergarten schools across the country. On the other hand, during the same period, the presence of 29,643 primary schools further clarifies the lesser emphasis given to the preprimary education from the ministry [4] [14] [19].

Hoot et al.'s study conducted on Early Education in Ethiopia: Progress and Prospects noted that, in Ethiopia, Early Childhood Care and Education (ECCE) is one of the most ignored areas [8]. Similarly, it seems a deserted area of research and therefore it needs attention. Hence, the dearth of research conducted calls me for the inescapable concern-the management of KG schools. Exclusively, my intention was to explore the status of the learning environment and the kind of pedagogy effected in Dilla University community KG School. From the pedagogical point of view several studies (e.g., [20]-[22]) confirmed that many pre-schools in different countries of the world focus on chalk and talk type of learning.

On top of this, in 2009, UNICEF's study of child friendly schools and an investigation by [20] conducted on the need for effective facility management in schools in Nigeria asserted that, the learning environment of KG schools have a significant influence on the rearing of children. The study further suggested that the physical learning environment must be able to accommodate all children in safe locations. It needs to be designed to meet the basic needs of children. Otherwise, "when the school environment is perceived as unwelcoming or threatening, attendance suffers” [12] [22]. 
Therefore, the study offered a considerable attention to the management of the KG school with reference to the conduciveness of the learning environment and the kind of pedagogy in place. In addition, it is believed that this study may help link the yawning gap between early childhood education policy intention and its outcomes. Consequently, the piece is devoted to achieve its purpose via the following basic questions:

1) To what extent the learning environment of Dilla University Community KG School is conducive to serve its purpose?

2) What pedagogical challenges and opportunities are in place in the management of Dilla University Community KG School?

\section{Methods and Procedures}

The research was guided by a constructivist paradigm. Ontologically, the approach allowed to investigate the issue understudy as it helps to find out the existing realities that are specific to the site. Because they are constructed by participants who experience the world from their own perspectives [23]. The epistemology of the paradigm also lets the construction of the findings which were developed via the mutual engagement and common understandings of both the participants and myself. Methodically, I have collected data from the natural setting, where I have started the concurrent data analysis. I spent quite a lot of time interviewing participants (about two hours with each), observing the study site (which includes the physical environment, the school facilities, and the actual teacher-student interactions), and analyzing documents [24].

In order to fully comprehend the experiences participants share, the study was conducted by the qualitative case study. Because the employment of the design helped me to conduct an in-depth study within its bounded system as it operates [25]. "Thick descriptions of contemporary phenomenon within its real-life context were employed from a variety of viewpoints in an attempt to understand the issue" [24] [26]. After I have collected the data, the analysis, and its interpretations were made, and a "rich, full picture of a research situation" were painted [27]. As a result, it enabled me to shed light on the management of KG schools with special reference to the learning environment and the practiced pedagogy in the study site.

\section{The Study Site}

The study was carried out at one of the twenty five KG schools of Dilla town of Gedeo zone in SNNPR, called Dilla University Community School. The school is selected as the site of the study because it is the only government school found in the vicinity. Moreover, as far as my knowledge is concerned no similar study was carried out in the site. Hence, the school is administered by Dilla University since it was established in 2001 Ethiopian Calendar (E.C.) to render services to the University staffs and the surrounding community. It accommodates a total of 179 (92 male and 87 female) children in five groups from nursery to upper KG levels. Eight female teachers who graduated from Early Childhood Care and Education-Teachers Training Institutes (ECCETTIs) with certificate undertake the teaching-learning process headed by one coordinator.

\section{Sampling and Participants}

Purposeful sampling method was employed to recruit participants of the study. Because the technique has helped me in selecting good key informants who were selfless, articulate, informative, and experienced with the theme of the study and setting [28]. To get a pertinent information six interview participants were chosen. The major rationale I have used smaller samples in this piece is that "it is expensive (expense of labor) and time consuming" [29]. Gay et al. also advised that "qualitative researchers must almost always deal with small samples, normally interacting over a long period of time and in great depth" [28]. Hence, the smaller number of samples enabled me to obtain the desired depth of data needed to achieve the purpose of the study.

Accordingly, on the basis of their teaching experiences in KG schools for at least 8 years and field of specializations two teachers whom I think potentially able to provide more comprehensive information were selected. Similarly, the school principal; the school supervisor; the school Parent Teacher Association (PTA) chairman; and the Early Childhood Care and Education (ECCE) expert of the town, who was in charge to oversee the school understudy by virtue of their current position were included. I considered their varied experiences provide rich, descriptive, and meaningful data that served the objective of this study. Similarly, the use of participants from different career structures offered the study a methodological strength than a single source [29]. 


\section{Data Gathering Tools}

Tools used to gather data from the research participants were semi-structured interview, observation and document analysis. In-depth interview was the major instrument employed to collect data in this study. The semistructured interview was the dominant data collection instrument of the study. Because it offered me an access to collect data that is inaccessible (e.g., via observation) [28]. It also helped me to establish rapport and solicit detailed information [29]. Above all, according to the advise forwarded by Patten the approach was not limited to the predetermined questions. For instance, too terse responses were enriched by additional questions [29].

Although the interview guiding questions were developed in English for the sake of better communication the interview was conducted in Amharic language. Discourses were undertaken in the preferred sites of the participants. As a novice qualitative researcher I have invited one of my senior academic staffs experienced in qualitative research to have his observation and support during the process of data collection. Thus, he assisted me the job of interviewing and collecting field notes [29]. In an attempt to better elicit information and uncover the interviewee's true positions a minimum of two hours were spent with each interviewee’s [26] [30]-[32].

The interview protocol facilitates the smooth and similar flow of events throughout the interview process. Hence, among other things, each of the interviewees were encouraged to describe the conduciveness of the school learning environment and the kind of pedagogy found in the study site. Thus, as its major purpose is used to "clear the air as well as to clear the mind" demographic information (such as: age, level of education, field of specialization, work experience, current position) were inquired before conducting the interviews [29].

Document analyses were also employed to get supportive ideas to the information gathered through semistructured interview and observation. In this regard national and regional ECCE policy documents, ECCE guidelines, students mark list, school minutes, class schedules, school reports, etc. were referred. The selection of these documents were based on the researcher's judgment in relation to the purpose of the study.

Besides, observations of the school environment and the exercised pedagogical orientation were made for ten working days. Data were collected using the checklist developed from the KG school standard of Southern Nations, Nationalities and People's Region (SNNPR) education bureau. From the international perspectives the KG school standards of Nigeria, Kosovo, and Rwanda has been taken in to account.

\section{Data Analysis}

The data gathered through semi structured interview, observation and document analysis were analyzed systematically. In line with the advice of [32], analyses and interpretation of data were made concurrently on daily basis along with the task of data collection [30] [32]. Through an intensive reading and rereading of each interview notes and examining for words or phrases concepts that repeat themselves were identified. Cross case analysis is used to categorize similar ideas that were gathered from participants on the same issue [29]. The themes of two guiding research questions were considered to develop major themes. The data were organized into open coding, and then creating major categories, and abstraction which finally resulted in sub-categories. For instance, I have coded emerging themes from all data and sorted out into six specific categories. Finally, data from observation and document analysis were compared and synchronized to the data from the interview.

\section{Validation Strategies}

To reduce the impact of bias on the data collected, several validation techniques were used to document the accuracy and value of the study. To establish the "dependability and trustworthiness" ${ }^{1}$ of the data and assure triangulation I have used multiple sources for obtaining data on the research topic [29]. Hence, I have interviewed six practitioners who assume five different positions such as: two school teachers, the principal, chairman of the Parent Teacher Association (PTA), the supervisor, and district education office KG expert. Thus, if various sources provide similar information, the data can be said to be corroborated [29]. To assure the quality of this research two of my senior $\mathrm{PhD}$ fellows assisted me during the time of data collection and analysis. With respect to this Patten confirmed that "researcher triangulation help reduce the possibility of the results of idiosyncratic views of one individual researcher" [29].

In an effort to keep a neutral viewpoint, I have reflected on my biases of the research topic and assumptions of

${ }^{1}$ The term "dependability" and "trustworthiness" in qualitative research loosely correspond to the terms "reliability” and "validity” in quantitative research [29]. 
the outcomes of the study prior to and during the research to maintain as impartial of a position as possible. I have personally reflected my professional career as a teacher and school manager at primary, secondary and university levels. Likewise, to be more transparent and for the benefit of the study I have disclosed my field of study from primary school certificate to Masters of educational planning and leadership in each occasion of contact and communication with the participants. I have also structured the research question and probing questions in such a way that did not guide the participant's responses in a predetermined direction.

Methodological coherence, appropriateness of the samples, collecting and analyzing data concurrently and thinking theoretically was followed as I undertake the study. The approach allowed me an opportunity to evaluate and propose a timely correction and ascertained the way forward. Prolonged engagement in the field and the triangulation of data sources were used to establish credibility [26]. From my observations, a thick description of each participant was constructed to help readers determine the transferability of the research. Dependability of the study was established through peer review by another researchers (two of my colleagues) trained in qualitative research throughout the research process. Additionally, member checks data analyses, interpretations, and conclusions were conducted to confirm credibility of the study.

\section{Ethical Considerations}

Data were gathered from the aforementioned sources through official permission of Dilla town education office and the school authorities. The consent of the individuals involved on the interview was strictly followed. For example, in order to obtain the interviewee's full cooperation, I have explained what I want from them and assured the ideas of the interview remains confidential. I have explained the objectives of the research, why he or she has been chosen and why he or she is going to be asked. However, though I have justified tape-recording the conversations none of them have accepted its utilization and thereby omitted. To manage this limitation apart from taking different pictures two major decisions enabled me to minimize its risk. First, team based interviewing and note taking helped me to collect adequate data. Second, spending a minimum of two hours with each interviewee gave me a chance to gather sufficient data.

\section{Results and Discussion}

This section presents the results of data collected from participants through interview, observation, and document analysis. For the sake of anonymity the following codes were included in the discussions. T1 and T2 refer to teacher participants. P3, B4, S5, and E6 represent the principal, parent teacher association (PTA) chairman, the supervisor, and the KG expert respectively. As shown in the table below pseudonym, code, sex, age, qualification, field of specialization, work experiences, and current positions were collected to understand their biographic information of the participants which implied their relevance to provide the research data. Of the six respondents five of them are females which indicated the KG staff of the study site is overwhelmed by female practitioners. As can be observed in the table below a minimum of 10 years work experiences, the pertinent field of specialization, and the assumed positions further strengthen the quality of the sources of data. In general, Table 1 summarizes their detailed biographic information.

The most significant implications for the management of KG schools with special reference to the learning

Table 1. Overview of participants’ profile.

\begin{tabular}{|c|c|c|c|c|c|c|c|}
\hline Pseudonym & Code & Sex & Age & Qualification & $\begin{array}{c}\text { Field of } \\
\text { Specialization }\end{array}$ & Work Experiences & Current Position \\
\hline Kokobe & $\mathrm{T} 1$ & $\mathrm{~F}$ & 34 & Certificate & $\mathrm{ECCE}^{*}$ & 10 years & The KG school teacher \\
\hline Hawi & $\mathrm{T} 2$ & $\mathrm{~F}$ & 38 & Certificate & $\mathrm{ECCE}^{*}$ & 11 years & The KG school teacher \\
\hline Sara & P3 & $\mathrm{F}$ & 33 & Certificate & $\mathrm{ECCE}^{*}$ & 11 years & The KG school Coordinator \\
\hline Olyad & B4 & M & 45 & MA & $\mathrm{EdPM}^{* *}$ & 20 years & $\begin{array}{c}\text { Chairman, Parent Teacher } \\
\text { Association (PTA) }\end{array}$ \\
\hline Yanet & S5 & $\mathrm{F}$ & 30 & BA & $\mathrm{CEE}^{* * *}$ & 10 years & Supervisor \\
\hline Tsehay & E6 & $\mathrm{F}$ & 36 & BA & $\mathrm{EdPM}^{* *}$ & 13 years & Expert \\
\hline
\end{tabular}

Early Childhood and Care Education (ECCE $\left.{ }^{*}\right)$, Educational Planning and Management (EdPM $\left.{ }^{* *}\right)$, Civics and Ethical Education $\left(\mathrm{CEE}^{* * *}\right)$. 
environment and the pedagogical approach of Dilla University community KG school in the view of the interviewees, clustered around two major themes and six sub-themes:

1) Learning environment (conduciveness)

a) Unfavorable learning environment

b) Commitment

c) Supervisory Support

d) Training and re-training

2) Pedagogy in place (Traditional vs Child-centered)

a) Mode of Assessment

b) Traditional pedagogy

The identified themes and sub-themes reflected the ideas of the participants of the study. The discussion that follows considers these themes, dwelling on the most frequently cited key issues.

\section{Learning Environment}

In each of the interview sessions, participants of the study were similarly asked one of the guiding questions of the study 'What do you think of the learning environment of Dilla University Community KG School?' followed by probing questions such as what makes KG schools environment child friendly? Do you think the school buildings and play grounds are to the standards? Why? What can you say about the rapport between the staff and the school management? And what kind of activity is in place to improve the situation? After data is collected, organized and systematically analyzed concepts which repeat themselves were labeled as themes and subthemes. To begin with, under one of the two major categories the conduciveness of learning environment sub-themes such as: unfavorable learning environment, commitment, supervisory support, training and retraining were discussed successively.

Unfavorable learning environment: Surprisingly, five of the interviewees were in consensus to respond the learning environment is not conducive to conduct a quality teaching and learning process. They underscore that the school compound is too narrow; the buildings are not originally constructed for the purpose; children are suffering from play grounds, it lacks clean portable water; it also possesses an age inappropriate latrine with poor sanitation; and, there is also a poor relationship between the school management and the staff. In general, they have concluded that the school environment is not child friendly and this is stemmed from the little attention given by the school management since the last six years. An observation made by one of my informants could be more telling:

I don't have the guts to say the learning environment is conducive. The compound is too narrow. The school compound needs to be sufficiently large to confer each child a space to move and explore. The large number of students which is added up to four hundred sixty from KG to grade seven complicates the situation. This is so to fill the demand gap of KG school of the University staff and to serve the community around as it is a university based school. [B4]

The above mentioned idea indicated that the size of the school compound as compared to the number of children is not adequate. Hence, most likely it seems negatively contributed to the conduciveness of the learning environment. Another teacher interviewee added that:

The general surrounding of the school is not safe and conducive for learning and teaching. For example, the compound is surrounded by bushy grasses $\cdots$ Consequently, it is not uncommon to hear a snake is found and killed $\cdots$ which is frustrating $\cdots$ (T1)

As per my observation Photograph 1 further clarify the scenario:

From the responses of many of the interviewees, I was also able to note that the KG school is not conducive to properly accomplish its intended objectives. This is manifested by the following interviewees in a row ${ }^{2}$ :

KG schools are not built for the purpose of preprimary school. The school has insufficient play ground because the compound could not accommodate the large number of students found in the school. Adding, the dining rooms are below the standard. There is lack of portable water service and a low standard toilet represents the school. [S5]

The school has no library or a corner with shelves within each classroom as a learning resource area for storing and displaying educational reference materials to nurture and $\cdots$ develop the culture of reading and research-

\footnotetext{
${ }^{2}$ Note that new paragraphs denote comments from different participants.
} 


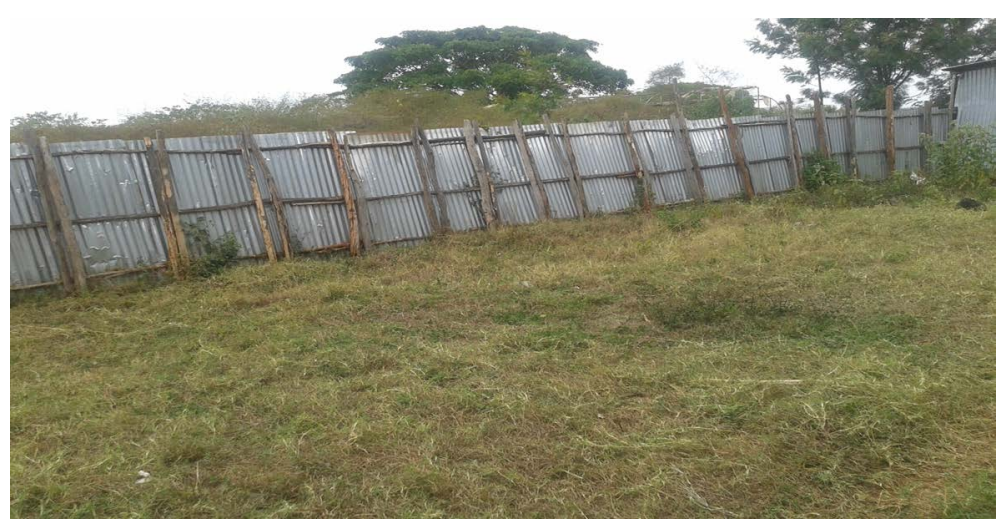

Photograph 1. Dilla university community KG school compound surrounded by bushy grasses (February 2014).

ing at their important ages. [T1]

Another participant noted that:

*.. As per my observations Dilla University KG school is suffered from a number of learning environment related problems. The school has no adequate play grounds, the school compound is also very narrow and hence it prohibits the free mobility of children. Since the last five years it has rendered its services in the same building which is not originally built for the purpose of KG school. [E6]

Concurred to the above idea from the school observation I have learned that the school buildings in use was not constructed for the purpose of KG. As a result, it is not child friendly. For example, the free physical mobility of the children has been limited. Besides, the children were vulnerable to injury in the case of sudden physical failure from the edges of the verandah (see the next Photograph 2).

The next Photograph 3 indicated one of the facilities planted for the school children. As can be observed from the photograph the toilet is not to the standard and age inappropriate (it may suffer children from injury and etc.). Hence, this may substantiate the existence of unfavorable school learning environment.

The next data forwarded by the school PTA chairman ascertained the severity of the issue under discussion.

The school has separate toilets with poor sanitation. There is also in short supply of pure water and sanitation facilities. For example, there is a poor waste removal system; sufficient garbage disposal bins are not arranged in all locations. [B4]

On the other hand, one of the teacher participants reflected her divergent view emphasizing the conduciveness of the learning environment.

I didn't see any problem the learning environment is quite good. We have clean toilets; children are provided with pure water; as usual, the transport service is going well. We have a positive relationship the school management is doing well. [T2]

It was a surprise! In the middle of the way the same teacher (T2) contradicted herself and pointed out as there was unfavorable learning environment. She forwarded it as:

I think the major responsibility of school management is creating a cooperative learning atmosphere. But, I fail to see any praise or incentives either from the school principal or the school board, what we call the PTA for better performances of the staff. Had it been implemented I think our relationship could not be hostile $\cdots$ [T2]

By way of summary, what has been found from the interviews are in agreement with my school observation and field notes. For instance, from the observation the school environment is not as per the standard set by the ministry of education (MoE) and the Southern Nation, Nationalities and People's Region (SNNPR) education office KG guideline. Besides, it was consistent with a study on assessment of quality in early childhood education conducted in Ekiti-State Nigeria by [33] which indicated that the school environment is unfriendly. Among other things, inadequate space, lack of easy access to safe drinking water, and hygienic sanitation. Similarly, a study report from [34] also supported that children throughout the world, whether in the North or the South nations are living in overcrowded, polluted and unsafe environments, which provide little opportunity for education and play $\cdots[34]$.

In general, among other things, as per this study Dilla University community KG school has been suffered from unfavorable learning environment. Thus, it calls for the determined school principal, teachers, supervisors, 


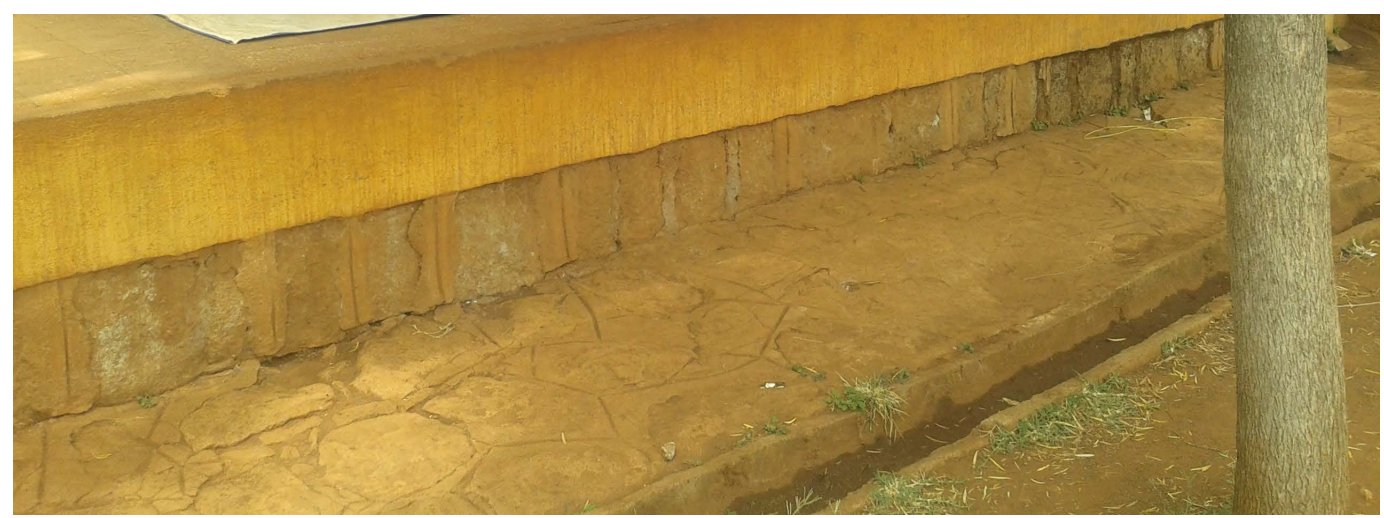

Photograph 2. Dilla university community KG school veranda of the classrooms (February 2014).

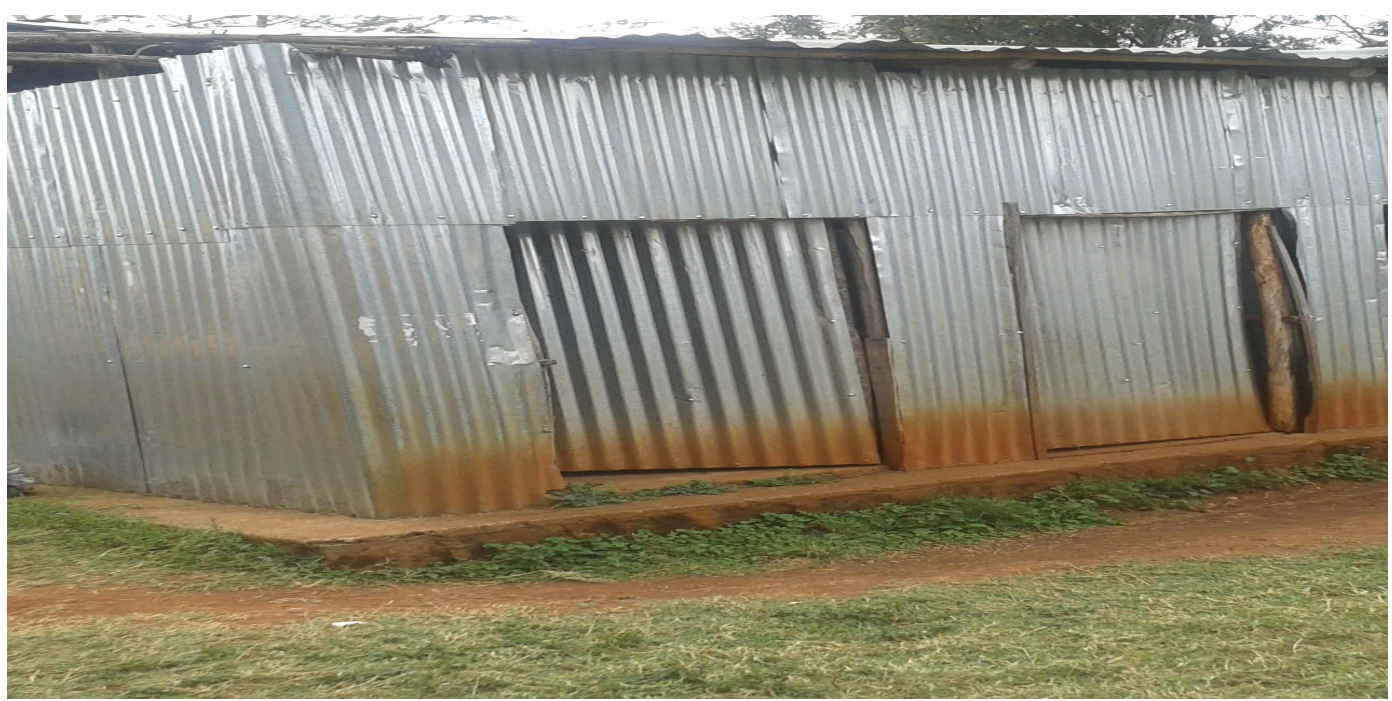

Photograph 3. Dilla university community KG School toilet (February 2014).

district experts, PTA members and other concerned authorities.

Commitment: Favorable school learning environment could be created and maintained mainly through the commitment of its management and the staff. Commitment could be one of the determinant factors for any job well done. On the contrary, a failure to possess the adequate amount of determination seems to celebrate ineffective task accomplishments. In line with this, to resolve the challenges discussed earlier (e.g., the narrow school spaces $\cdots$ ) the delayed KG school building is a good indicative of the poor commitment from the school management. One of the interviewee added:

What worries me is the attempt from the school management does not suffice to improve the harsh condition of the school environment. '- Year after year I haven't seen changes in the school learning environment things remain the same. [T1]

The next participants view also indicated the absence of commitment. She stated that:

As compared to other KG schools found in the vicinity, though better funds were allocated from the university it fails to serve the community to the necessary extent. The nonexistence of pedagogical center, library and play grounds characterizes the school. [T2]

The following data snippet also revealed the extent of emphasis given to the construction of school. It also shed light on the idea of the poorly determined school leadership.

...indeed, the school has started its functioning before five or six years ago. However, to resolve the problem (the narrowed school compound) year ago a corner stone was laid by the university to build its own KG school. Yet, to date nothing is observed to commence the construction. (B4)

Effective communication can be concerned as one of the factors of a committed school leadership. But, what 
was explained from the woreda KG expert (one of my interviewees) did not support it. It runs as:

There is a weak reporting system which is related to the poor management of the school. They are very much reluctant in their overall relationship with the woreda education office. There is also a poor teachers and school management relationship. [E6]

From the aforementioned views lack of commitment characterizes the school management. In line with this, one participant (T2) summarized “... I think the management of the school seems not worried to create a helpful learning environment so that children are not treated well.” Apart from that, the well functioning of KG schools management enables children to collect their maximal benefit. For instance, a good number of children and families benefit throughout the world participating in high standard, proven early childhood programs run by devoted and skilled professionals [17]. Otherwise, children who do not have the opportunity to enjoy a conducive learning environment such as lack of play grounds and other facilities would be at increased risk for abnormal development and deviant behavior [38].

In conclusion, participants view indicated that there has been a serious problem to find a determined KG school management and its staff. The absence of committed practitioners could negatively affect the development of children. Thus, it could have been good to have a supervisory intervention.

Supervisory Support: Views of participants were equally represented under this theme, typified in comments relating to inadequate supervisory support in an attempt to improve the conditions of the learning environment of the school. The subsequent interview participants view indicated that supervisory support was rendered sporadically. One interviewee (the district supervisor) asserted that:

-.We conduct the services of supervision only twice in a year. For instance, I didn't have the time to make it consistent. Because, I'm busy as my job is not only limited to oversee KG schools but also to the primary and secondary schools of the town. [S5]

The school supervisory practices of the KG school were limited to one ministry (the ministry of education). From my document analysis, as stipulated in the 2010 ECCE policy document of Ethiopia the childhood care and education effort shall be a joint venture of the three ministries in the creation and development of conducive learning atmosphere. However, it remains as the sole responsibility of MoE. This seems complicated the supervisory endeavor challenging. She (the supervisor) added that: "I think the issue of ECCE is the concern of three ministries. But, I couldn't see any cooperation from both: the health department of the town and from the women, youth, and child affairs office of the town.” A teacher interviewee also added that:

I could see fragile attempts from the management of the school including the PTA's supervising the school environment and strive to improve the current status of the learning environment. [T1]

The presence of uninterrupted supervisory practices has a pivotal role in improving the school working conditions in general, and the learning environment in particular. Nevertheless, many interviewees reflected about the poor practices of supervisory services which should not be. In relation to this, the school principal stated:

I think it is because of less supervisory practices that we have developed a weak learning environment. Had there been a series of supervision the condition of the learning environment namely our relationship might be at the positive end. [P3]

The frequent provision of supervision enabled KG school practitioners to be encouraged, committed, and deliver their services in accordance with the general purposes of the school. If this is so, the learning environment would be created and maintained child friendly. Yet, if the reverse holds true like the result of this study training and re-training is likely to tackle the problem.

Training and re-training: The need for sound KG management training and retraining was equally represented in participants' comments. The provision of ECCE oriented short and or long term training of any kind could benefit practitioners. Nonetheless, all participants of the study were in consensus to reveal that to date training of any form were not given to them. This witnessed the little attention given to the program in general and the human resource development in particular. One of the interviewees asserted the scenario as:

I didn't see any professional training offered to KG teachers or any other education official on the teaching methodology of preprimary schools either from the government or NGOs. [S5]

Another interviewee also summed up:

The managers of the school have no adequate training in the area of KG school management. I think training would help KG school administrators acquire the basics of KG school management. They might be in short of knowledge and skills needed to improve the school environment for the benefits of kids. [T2]

The subsequent review further strengthens the need of ongoing trainings and re-trainings. Concurred with this, 
[17] recommendation described that "children benefit through participating in early childhood programs run by skilled school administrators". Similarly, [35] added that the care and education of children is an undertaking so pertinent and should only be carried out by professionals with a high degree of professionalism, knowledge, and skills. Nevertheless, none of the interviewees revealed that the school management has trainings of any kind in the area of ECCE.

\section{Pedagogy in Place}

"What pedagogical challenges and opportunities are in place in the management of Dilla University Community KG School?” was the second guiding question of the study. Thereby, via semi-structured interviews it appeared as the major question followed by the subsequent probing questions such as: Do you think the school provides appropriate and adequate teaching learning materials? Do you think the school management provides appropriate and adequate teaching learning materials? To what extent play is considered as the pedagogy of the child? Which kind of pedagogical approach has been exercised? Why do you think so? How is the process of children's learning assessment going? Have you attended professional development trainings related to early childhood care and education? Do you think that class size is to the standard? What do you feel about the supervisory supports rendered to the school practitioners?

In the course of answering to these questions, one participant said that "I think the school has myriads of challenges of which the problem in pedagogy is the worst." It coincides to the argument of the [36] which revealed that "Not all teachers embrace child-centered methods either. For one thing, they're a lot more work, demanding more time, more energy, and more creativity. It may be easier for a teacher when the children just sit still and listen to what they're told.” The second major theme of the study embarked on the kind of exercised pedagogy. Thus, two sub-themes of the section: mode of assessment and traditional pedagogy were explored consecutively.

Mode of assessment: In the process of teaching and learning the mode of assessment and the kind of pedagogy have a symbiotic relationships. Their nature of interdependency enabled them to push and pull each other. Hence, the kind of assessment whether formative or summative can be one of the indicatives of the employed teaching methodology. Study participants data revealed that the assessment mechanism of the school is against the developmental requirement of the children. In line with this argument majority of the interviewees corroborated the following idea:

Above all the mode of assessment which has been employed in the KG schools is abnormal. As educator I think this is not appropriate and could not meet the developmental needs and maturity of the children. I could see children of four and five years old tested a written exam of courses out fifty percent like a university student which deviates from the major domains of child development. [S5]

In addition, as per the document analysis and observation, the mode of assessment that has been implemented and the amount of courses to be offered seem not age appropriate and developmental. For instance, my document analysis on the students report card and roster of the first semester of 2006 E.C depicted that twelve courses such as Amharic, English, Math in Amharic, Environmental science in English, English handwriting, Spoken English, Computer "not yet implemented", Art, Music, Story, Sport, and Play. I was able to realize that all these have been offered from nursery to upper KG. With regards to assessment tests cover $70 \%$ of the entire evaluation mechanism (test 1 and 2 accounts 20\%; mid exam 30\%; and final exam 30\%). The remaining 30\% will include (class activity $5 \%$, worksheet $10 \%$, exercise book neatness 15\%). Besides, I have observed that a series of worksheets and excerpts (four to five times per semester) to be worked out and read as home take assignments have been dispatched. I think this keeps children busy and overwhelmed to recite now and then. Yet, it consumes their play time and makes them scarify the non-cognitive goals of the level except the cognitive dimension.

The large class size is also considered as one of the most important causes contributed to un child-friendly mode of assessment. One of the interviewees substantiate the idea as hereunder:

To render a good services and manage the classroom as per the need and talents of my children I have been facing a challenge. My difficulty is the large class size. $\cdots$ look! Now I have fifty one students where the standard is below twenty five students in KG. I'm also busy in assessing them. So who is going to blame me for mistreatments of the children? Yet, I'm striving to do my job. The *-teacher-to-child ratio should be maintained at a level that allows teachers to give the individualized attention that each child requires. I think it could have not been a problem if the governing body of the school built its own school. [T2] 
Likewise, my document analysis confirmed the presence of fifty one children in the mentioned lower KG class and the school average class size of 35.8 students per class which is beyond the international standard (twenty). In relation to the aforementioned idea the effectiveness of the school management is critical for keeping children safe and involved in age appropriate activities.

The children to care providers ratio depends on their age, the facility and the nation's resources [22]. However, according to [22] worldwide a maximum of 20 children per caregiver is recommended to 4- to 6-year-old range.

In conclusion, the larger the class size depicted the exam oriented mode of assessment. Similarly, as noted earlier the age inappropriate mode of assessment exemplifies the traditional teacher centered pedagogy.

Traditional Pedagogy: The teacher-dominated teaching methodology which sometimes referred as traditional pedagogy seemed surfaced in the study site. Regardless of their failure to implement the child friendly approach participants were in favor of the play oriented child-centered pedagogy. Besides, the interviewed participants were in harmony indicating the unproductive management system in realizing child-centered pedagogy. One participant commented:

Frankly speaking, the kind of pedagogy which has been implemented in our school is traditional. I didn't see the difference with the primary schools. To my understanding the child-friendly pedagogy is not yet materialized. A good example is the poor mode of assessment in place. Children aged three, four, five and six are tasked to take a fifty percent written exams in courses such as Math, English and Amharic. I think this is not a developmentally appropriate pedagogy rather it is indicative of rote learning. [B4]

My classroom observation confirmed that the child-centered pedagogy is not yet realized. For instance, the classroom arrangements (the fixed blackboard, the posted alphabets $\cdots$ ) denoted the chalk and talk pedagogy. The following Photograph 4 clarifies the scenario:

Supervisors view further strengthens the issue discussed earlier. She noted it as:

From my experiences play-oriented pedagogy is not fully implemented in the KG program. Most of the time when I observe the pedagogical orientation they use a kind of chalk and talk type of teaching which is similar to primary schools. Nonetheless, we are striving to curb it for the benefit of the children. [S6]

On the other hand, as per my observation, play, which is usually referred as pedagogy of the child is

not yet adequately materialized. Many of the interviewees were in consensus in supporting this idea. For example, one respondent asserted that:

It is worrisome to think about the opportunities offered to play. I believe early childhood period has to be dominated by play; but because of lack of playing materials children are exempted from learning. I think it is possible to fulfill the playing tools $\cdots$ I don't think this is because of lack of money. What matters is - the way we think and act. [S5]

Another interviewee added:

The school is ill-equipped with play materials not to say... there are no play materials [S5]. The comments reflect the prohibition of children from play-oriented mode of child rearing pedagogy. Yet, according to [37] [38] children who go to playful kindergartens rather than didactic in countries as diverse as Germany, China, Japan, USA and Finland excelled over the others in every area measured-physical, emotional, social, and intellectual development. They also remained consistent in getting the highest scores on the reputed international Program for International Student Assessment (PISA) exam for 15-year-olds [37].
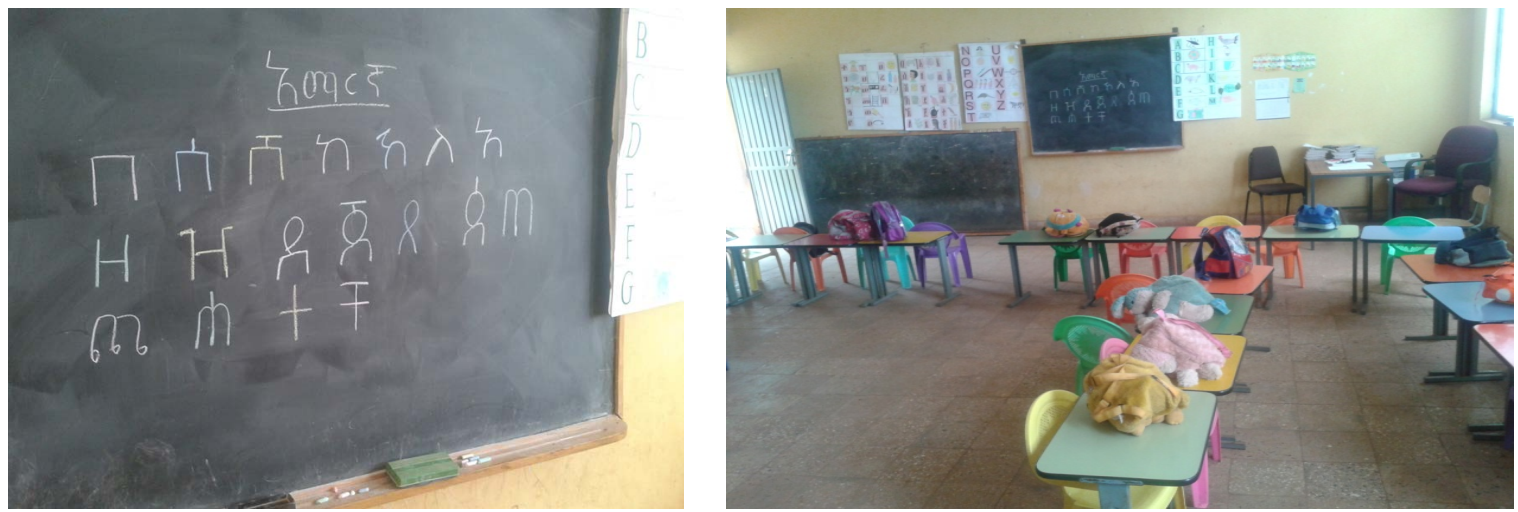

Photograph 4. Dilla university community KG school classroom arranged for traditional pedagogy (February 2014). 
Apart from that, if children are deprived from adequate amount of play problems mushroom [38]. In relation to this, my study is consistent with [39]. The studies show that "formal approaches to teaching young children are counterproductive and can hinder young children's learning, generating higher anxiety and lower self-esteem" [39].

To sum up, the existence of the child inappropriate assessment mechanism and the employment of the outdated pedagogy were better described by the words of one of the teacher respondents as here under:

As far as the pedagogical orientation and the mode of assessment is concerned the difference between our KG school and the primary one is invisible. More or less we have been employing the same pattern. I don't think we are correct but the large class size, the inadequacy of the teaching materials, and perhaps the knowledge and skills gap that might be observed in some of us influenced our positive developments. [T1]

\section{Summary, Conclusion and Recommendations}

The previous section reported on and discussed the results of the study. The purpose of this part is to summarize and draw conclusions regarding the main findings of the study. Recommendations for future studies are also forwarded.

\section{Summary}

In this study the condition of Dilla University Community KG school management with reference to the status of the learning environment and its pedagogical orientation is found with a number of drawbacks. First, the learning environment is not child friendly to conduct a quality teaching and learning process. The unfriendliness of school environment is mainly characterized by: narrow school compound; in adequate play grounds; lack of easy access to safe drinking water; lack of hygienic and age appropriate toilets; the school buildings are not originally constructed for the purpose; and the poor relationship between the school management and the staff can manifest the quandary. In general, children are suffering from overcrowded and unsafe environments, which provide little opportunity for learning and play.

Second, participants of the study highlighted that child-friendly pedagogy is not yet adequately materialized. The interviewed participants were also in harmony indicating the employed mode of assessment did not consider the developmental needs and maturity of children. Besides, the school is attributed to the large class size; and the provision of insufficient and nonappearances of learning materials and play equipment both indoor and outdoor.

\section{Conclusions}

In conclusion, the above findings have implications for the appropriate development of children at the school. Children of the school have suffered from lack of conducive learning environment. Besides, the traditional age inappropriate, chalk and talk dominated pedagogy could have negative repercussions in the optimal development of the children. For instance, the mere transmission of factual knowledge could shackle the emotional, social, physical, and creative abilities of children as it is limited to cognitive. The exam oriented assessment mechanism of the school further exemplifies the low-key given to make the school child-friendly. The major sources of the shortcomings seem associated to the inefficient school management, their poor commitment; lack of supervisory support; and the absence of ECCE oriented professional development trainings.

Despite this fact, children need time, space, materials and the support of skilled and dedicated early childhood educators in order to become a dependable future generation. Otherwise, a KG school that does not adequately address the socio-emotional needs of young children runs the risk of contributing to the development and expression of challenging behaviors. Hence, this calls for the due attention of the concerned authorities.

\section{Recommendations}

Based on the findings of the study the following recommendations are forwarded. KG school managers should have a good knowledge of child development and therefore appropriate professional training has to be designed and effected rather than allowing rule of thumb type of leadership.

1) Well-trained facilitators understand that children consistently respond in a positive way to warm, nurturing caregivers who are capable of identifying with children's needs and concerns. Therefore, ongoing caregivers' 
professional development trainings should be in place.

2) Uninterrupted professional support boosts the implementation capacity of the child centers. Hence, assigning professionally competent, wily, and responsible supervisors is indispensable.

3) As it goes against the developmental maturity of children the manifestation of rote learning-the test-driven culture of assessment should diminish. Instead the assessment may cover a broad range of children's activities and abilities.

4) All concerned bodies should put concerted effort in creating and developing a playful and child-appropriate learning environment.

Besides, all possible factors which contribute to examine the management of KG schools are not exhausted in this study as it is limited to the learning environment and pedagogy. Therefore, it will be appropriate to include other factors in the future studies and or similar study is also encouraged to see its dependability. Therefore, the study offers a vantage point from which further studies might be undertaken so that several research themes surfaced. The eight areas I feel should be explored include: (a) Assessment of quality in early childhood education; (b) The assessment mechanism of KG schools; (c) The professional development training of KG school practitioners; (d) The role of supervisors in KG schools; (e) The practices of KG schools; (f) The school-community relationship in KG schools; (g) KG school teachers' awareness on child-centered pedagogy vs teachers-centered pedagogy; and, (f) The competence of KG schools management.

\section{References}

[1] Nadeem, N.A., Jabeen, G. and Bilquees, S. (2013) Use of Play Way Method and Creating Healthy Environment in Pre-Primary School of Srinagar District: An Evaluative Study. Journal of Education Research and Behavioral Sciences 2, 167-176.

[2] Rao, V.K. (2009) Early Childhood Care and Education. Commonwealth Publishers, New Delhi.

[3] Tassew, W. (2011) The Effects of Early Childhood Education Attendance on Cognitive Development: Evidence from Urban Ethiopia. The CSAE Conference on Economic Development in Africa, St Catherine's College, Oxford.

[4] Woodhead, M., Ames, P., Vennam, U., Abebe, W. and Streuli, N. (2009) Equity and Quality? Challenges for Early Childhood and Primary Education in Ethiopia, India and Peru. Working Paper No. 55, Studies in Early Childhood Transitions, Bernard van Leer Foundation, The Hague.

[5] The World Bank (2007) Early Child Development from Measurement to Action: A Priority for Growth and Equity. Library of Congress, Washington DC. http://web.worldbank.org

[6] Bing, K.W., Young, M.E. and Cai, J. (2012) Early Child Development in China. Breaking the Cycle of Poverty and Improving Future Competitiveness. World Bank, Washington DC.

[7] Knitzer, J. and Klein, L. (2006) Pathways to Early School Success. Effective Preschool Curricula and Teaching Strategies. Issue Brief No. 2.

[8] Hoot, J., Szente, J. and Mebratu, B. (2004) Early Education in Ethiopia: Progress and Prospects. Early Childhood Education Journal, 32, 3-8. http://dx.doi.org/10.1023/B:ECEJ.0000039637.29327.d2

[9] Brock, K. (2012) Ways Forward for early Learning in Ethiopia. Young Lives, Oxford Department of International Development (ODID) University of Oxford, Oxford, UK.

[10] Ministry of Education (2010) National Policy Framework for Early Childhood Care and Education (ECCE) in Ethiopia. Government of Ethiopia, Addis Ababa.

[11] Ministry of Education (2010) Curriculum Framework for Ethiopian Education (KG-Grade 12). AM Printing and Packaging PLC, Addis Ababa.

[12] Ministry of Education (2002) The Education and Training Policy and Its Implementation. Government of Ethiopia, Addis Ababa.

[13] City Government of Addis Ababa Bureau of Finance and Economic Development (2013) Socio-Economic Profile of Addis Ababa for the Year 2004 E.C/2011/12G.C. Addis Ababa.

[14] Tirussew, T., Tezera, F., Workneh, N. and Gudaye, E. (2001) Early Childhood Care and Development Interventions in Ethiopia and Child Labor in Ethiopia: Its Conditions and Link with Early Childhood Education. A Directory of Early Child Development Projects in Africa, Unpublished.

[15] Haque, M.N., Nasrin, S., Yesmin, M.N. and Biswas, M.H.A. (2013) Universal Pre-Primary Education: A Comparative Study. American Journal of Educational Research, 1, 31-36. http://dx.doi.org/10.12691/education-1-1-7

[16] UNESCO (2010) Country-Case Studies on Early Childhood Care and Education (Ecce) in Selected Sub-Saharan African Countries 2007/2008, UNESCO. 
[17] Calman, L. and Tarr-Whelan, L. (2005) Early Childhood Education for All: A Wise Investment. Lega Momentum, New York.

[18] Early Childhood Development and Education (2009) Early Childhood Development and Education. Proceedings of the African Conference on Child Abuse and Neglect, Addis Ababa, 4-6 May 2009.

[19] Ministry of Education (2012) Education Statistics Annual Abstract 2004 E.C (2011-12 G.C). Education Management Information System (EMIS), Addis Ababa.

[20] Asiabaka, I.P. (2008) The Need for Effective Facility Management in Schools in Nigeria. New York Science Journal, 1, 10-20. http://www.sciencepub.org

[21] Jalongo, M.R., Fennimore, B.S., Pattnaik, J., Laverick, D.M., Brewster, J. and Mutuku, M. (2004) Blended Perspectives: A Global Vision for High-Quality. Early Childhood Education Early Childhood Education Journal, 32, 143-147. http://dx.doi.org/10.1023/B:ECEJ.0000048966.13626.be

[22] UNICEF (2009) Child-Friendly Schools Manual. UNICEF, New York.

[23] Guba, E.G. and Lincoln, Y.S. (1994) Competing Paradigms in Qualitative Research. Handbook of Qualitative Research, 2, 163-194.

[24] Lincoln, Y.S. and Guba, E.G. (1985) Naturalistic Inquiry. Sage, Newbury Park.

[25] Johnson, R.B. and Christensen, L.B. (2008) Educational Research: Quantitative, Qualitative, and Mixed Approaches. 3rd Edition, Sage Publications, Inc., Lose Angeles.

[26] Creswell, J. (2007) Qualitative Inquiry \& Research Design: Choosing among the Five Approaches. Sage Publications, Thousand Oaks.

[27] Wright, H.K. (2002/3) Qualitative Research in Education: From an Attractive Nuisance to a Dizzying Array of Traditions and Possibilities. Tennessee Education, 32/33, 7-15.

[28] Gay, L.R., Mills, G.E. and Airasian, P. (2009) Educational Research Competencies for Analysis and Applications. Pearson, Columbus.

[29] Patten, M.L. (2005) Understanding Research Methods: An Overview of the Essentials. 5th Edition, Pyrczak Publishing, Glendale.

[30] Bogdan, R. and Biklen, S. (2007) Qualitative Research for Education: An Introduction to Theories and Methods. Pearson Education, Boston.

[31] Corbetta, P. (2003) Social Research: Theory Methods and Techniques. SAGE Publications Ltd., London.

[32] Neuman, W.L. (2007) Basics of Social Research Methods: Qualitative and Quantitative Approaches. 2nd Edition, Allyn and Bacon, Boston.

[33] Olaleye, O., Florence, O. and Omotayo, K.A. (2009) Assessment of Quality in Early Childhood Education in Ekiti-State Nigeria. World Applied Sciences Journal, 7, 683-688.

[34] Malone, K. (2006) Building a Child Friendly Community, Children’s Research Workshops Pilot Study Report. City of Bendigo, Bendigo.

[35] Lynn, A. (2012) Vital Voices for Vital Years: A Study of Leaders’ Perspectives on Improving the Early Childhood Sector in Singapore. Lien Foundation, Singapore.

[36] International Step by Step Association (2004) Building Open Societies through Quality Early Childhood Care and Education: Case Studies of the Step by Step Program. Step by Step Case Study Researchers at the Central European University Conference Center.

[37] Miller, E. and Almon, J. (2009) Crisis in the Kindergarten: Why Children Need to Play in School. The Alliance for Childhood. http://www.thestrong.org/sites/default/files/play.../Crisis_in_Kindergarten.pdf

[38] Nespeca, S.M. (2012) The Importance of Play, Particularly Constructive Play, in Public Library Programming. Association for Library Service to Children, ALSC's Board of Directors.

[39] Siraj-Blatchford, I., Sylva, K., Muttock, S., Gilden, R. and Bell, D. (2002) Researching Effective Pedagogy in the Early Years. University of London, Institute of Education, Department of Educational Studies, Norwich. 


\section{Appendix}

In Figure 1 the five themes (child, learning environment, pedagogy, management, and the tire) of a vehicle symbolizes the following ideas:

Child: Under the auspices of the KG school management-a child is found at the center as they deserve the maximum care and attention.

Learning environment: The green color depicts for the holistic development of a child and the learning environment should be child friendly and safe as it interacts to the environment.

Pedagogy: The bright color symbolizes if early childhood practitioners approach children with playful and loving atmosphere their future could be well enough.

Management: The position of the school management implies its responsibility in the process of making dependable citizens of the nation. If they are committed and professionally competent they can drive the fate of children towards the positive end.

Tire: the tire symbolizes the whole system "the whole is greater than the sum of its parts" [25]. Components such as the learning environment, the pedagogical orientation and the school management, and the child depict the relationship and interdependency and the need for better child development. Besides, as it also represents the vehicle if it is driven properly it can take children to their destinations safely otherwise vice versa. The strength, durability and flexibility of the tire also revealed the outcome of quality early childhood education which may resulted in the creation of competent, lifelong desirable behavior, and adaptive nature of well reared child respectively.

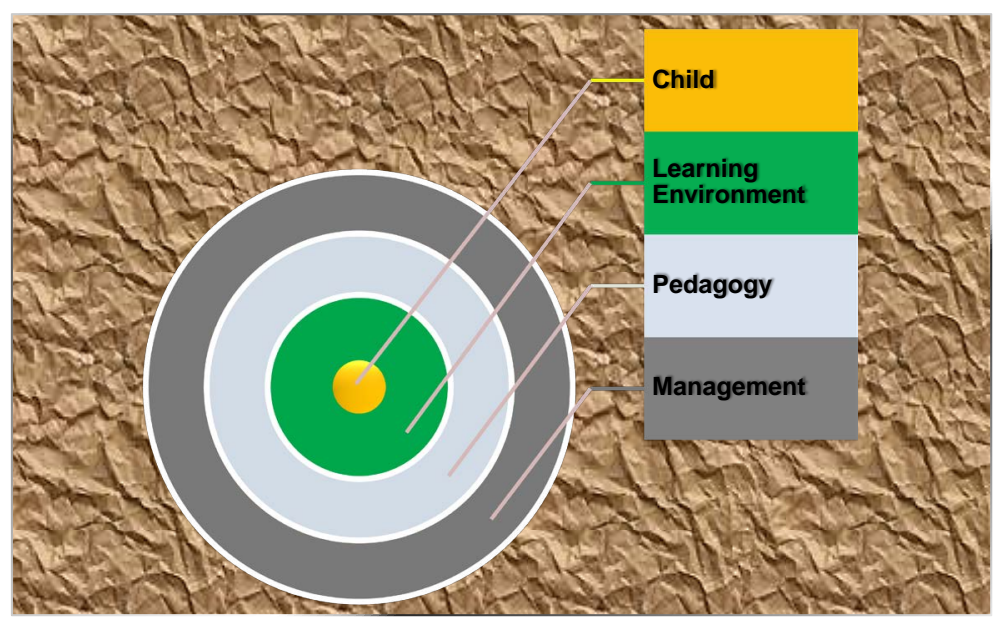

Figure 1. The conceptual frame work of the study developed by the researcher. 